Working

Paper

Department

of Economics

$\mathrm{Ca}^{\prime}$ Foscari University of

Venice

Barbara Buchner

Carlo Carraro

Regional and sub-global blocs.

A game-theoretic perspective on bottom-up climate

regimes 


\title{
Regional and sub-global climate blocs. \\ A game-theoretic perspective on bottom-up climate regimes
}

\author{
Barbara Buchner \\ Fondazione Eni Enrico Mattei \\ Carlo Carraro \\ University of Venice, Fondazione Eni Enrico Mattei, CEPR, CESifo and CEPS
}

\begin{abstract}
No international regime on climate change is going to be fully effective in controlling GHG emissions without the involvement of countries such as China, India, the United States, Australia, and possibly other developing countries. This highlights an unambiguous weakness of the Kyoto Protocol, where the aforementioned countries either have no binding emission targets or have decided not to comply with their targets. Therefore, when discussing possible post-Kyoto scenarios, it is crucial to prioritise participation incentives for all countries, especially those without explicit or with insufficient abatement targets. This paper offers a bottom-up game-theoretic perspective on participation incentives. Rather than focusing on issue linkage, transfers or burden sharing as tools to enhance the incentives to participate in a climate agreement, this paper aims at exploring whether a different policy approach could lead more countries to adopt effective climate control policies. This policy approach is explicitly bottom-up, namely it gives each country the freedom to sign agreements and deals, bilaterally or multilaterally, with other countries, without being constrained by any global protocol or convention. This study provides a game-theoretic assessment of this policy approach and then evaluates empirically the possible endogenous emergence of single or multiple climate coalitions. Welfare and technological consequences of different multiple bloc climate regimes will be assessed and their overall environmental effectiveness will be discussed.
\end{abstract}

\section{Keywords}

Agreements, Climate, Incentives, Negotiations, Policy

JEL Codes

C72, H23, Q25, Q28

Address for correspondence:

Carlo Carraro

Department of Economics

Ca' Foscari University of Venice Cannaregio 873, Fondamenta S.Giobbe 30121 Venezia - Italy

Phone: (++39) 0412349166 Fax: (++39) 0412349176 e-mail: ccarraro@unive.it

This Working Paper (o QD se in inglese) is published under the auspices of the Department of Economics of the Ca' Foscari University of Venice. Opinions expressed herein are those of the authors and not those of the Department. The Working Paper series (o QD se in inglese) is designed to divulge preliminary or incomplete work, circulated to favour discussion and comments. Citation of this paper should consider its provisional character

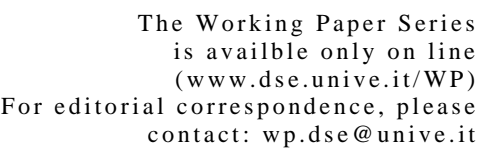

The Working Paper Series is availble only on line (www.dse.unive.it/WP)

For editorial correspondence, please contact:wp.dse@unive.it

Department of Economics

Ca' Foscari University of Venice

Cannaregio 873, Fondamenta San Giobbe

30121 Venice Italy

Fax: ++390412349210 


\section{Introduction}

Climate negotiations are a complex dynamic process. Climate change control, being a global public good, can hardly be attained on a voluntary basis. At the same time, there is no supranational authority that can impose an effective international climate policy. Therefore, an international cooperative and voluntary agreement to curb global greenhouse gas (GHG) emissions seems to be the only way to combat climate change. However, because of free-riding incentives and strong economic and environmental asymmetries, it is unlikely that an international climate agreement will be signed by a large number of countries (Carraro and Siniscalco, 1993; Botteon and Carraro, 1997), unless its goals are not significantly different from those of a non-cooperative, business-as-usual, domestic policy (Barrett, 1994).

Nonetheless, the diplomacy of climate policy has made considerable progress in the last ten years. International climate policy has recently enjoyed its first note-worthy success. The Kyoto Protocol has come into force on February 16, 2005 and countries world-wide have already started discussions on a possible, better designed, post-2012 climate agreement.

However, the US defection from the Kyoto Protocol and the lack of explicit abatement targets for the main developing countries - China and India above all - have largely reduced the environmental effectiveness of the Kyoto Protocol, which remains far from achieving the objective of stabilising GHG concentrations at about 500-550 ppmv. Therefore, several policy proposals have emerged that could be adopted after 2012 and that could enhance the incentives to participate in a climate agreement (Cf. Aldy 
et al., 2003; Aldy, Barrett and Stavins, 2003; Bodansky, 2004; Baumert et al., 2002; CNRS/LEPII-EPE et al., 2003; OECD/IEA, 2002). Some of these proposals are based on targets and timetables, others on the adoption of global economic instruments, others on technological development and cooperation, and others are a mix of different approaches (Cf. Barrett, 2001; Nordhaus, 2001; Kopp et al., 1999; Pizer, 1999; McKibbin and Wilcoxen, 1997).

Among the many existing proposals, there is one that has both a theoretical and an empirical appeal. This proposal was launched several years ago by Carraro $(1998,1999)$ - where a game-theory argument was the main driver - and more recently by other authors (Cf. Egenhofer and Legge, 2001; Egenhofer, Hager and Legge, 2001; Stewart and Wiener, 2003; Reinstein, 2004) on the basis of less theoretical considerations. The basic idea is to adopt a bottom-up, country-driven approach to defining national commitments. Instead of a top-down, international negotiation of national emission targets, each country would determine its contribution to a cooperative effort to curb GHGs and choose the partners with whom it intends to cooperate. In a process analogous to trade negotiations, each country would put its offer of commitments on the negotiating table and invite proposals from other countries for similar commitments.

This basic idea may lead to a quite fragmented climate regime and to the formation of climate blocs (regional coalitions for example) in much the same way as is now emerging in trade negotiations. This should not be surprising. In substance, even though not in form, the Kyoto Protocol already reflects agreements among several different coalitions. It incorporates special provisions for several different groups of countries. The Non-Annex B countries have no commitments and can benefit from emission reduction investments through the CDM. The most vulnerable Non-Annex B countries can also receive financial assistance for adaptation from the levy imposed on the CDM (and possibly on the other mechanisms). 
The European Union has the ability under Article 4 to redistribute the emissions reduction burden. Australia ha obtained/negotiated a special provision on land use emissions in Article 3.7. ${ }^{1}$

In addition, the lesson that can be derived from trade negotiations consistently tells us that progress on trade liberalisation can be achieved mostly through regional agreements, at least in the coming years. ${ }^{2}$ In international trade, the "resurgence" of regionalism has thus become a crucial subject, underscored by the formation of competing customs unions and the debate about free trade areas. Substantial attention has been focused on the efficiency and implications of these regional or sub-global cooperations (Cf. Baldwin, 1993; Casella, 1995; Bloch and Ferrer, 1999; Bond and Syropoulos, 1996; Krugman, 1991; Yi, 1996a, 1996b and 1998).

In particular, several authors have pointed out that Regional Trade Agreements (RTAs) may seem to be contradictory, but they can often actually support the WTO’s multilateral trading system (Cf. Sampson and Woolcock, 2003). Regional agreements have allowed groups of countries to negotiate rules and commitments that go beyond what was previously possible multilaterally. In turn, some of these rules have paved the way for agreements within the WTO. Services, intellectual property, environmental standards, investment and competition policies are all issues that were raised in regional negotiations and later developed into agreements or topics of

\footnotetext{
${ }^{1}$ As has been stressed by Egenhofer and Legge (2001), "it is increasingly becoming clear, [that] the Kyoto Protocol is less a global agreement than a set of differing regional approaches".

${ }^{2}$ The strong increase in the number of trade bloc agreements registered with the World Trade Organisation is discussed in Tjornhom (2000) and Boonekamp (2003). Some 250 regional trade agreements (RTAs) have been notified to the GATT/WTO up to December 2002, of which 130 were notified after January 1995 . Over 170 RTAs are currently in force. An additional 70 are estimated to be operational although not yet notified. By the end of 2005, if RTAs reportedly planned or already under negotiation are concluded, the total number of RTAs in force might well number up to 300. As of October 2003, all 146 WTO Members, with the exception of Mongolia, participate in or are actively negotiating regional trade agreements.
} 
discussion in the WTO. ${ }^{3}$ For these reasons, on 6 February 1996, the WTO General Council created the Regional Trade Agreements Committee. Its purpose is to examine regional groups and to assess whether they are consistent with WTO rules. The committee is also examining how regional arrangements might affect the multilateral trading system, and what the relationship between regional and multilateral arrangements might be.

Can something similar take place in climate negotiations? Can countries find more incentives to participate in regional or sub-global climate agreements than in a global agreement? Will regional or sub-global climate blocs increase the amount of abated GHG emissions? Will they help to achieve a better control of climate change?

This paper answers the above questions from a game-theoretic perspective, by providing both theoretical and empirical arguments in favour of regional and sub-global climate blocs. The next section will focus on theoretical analyses. It will provide a survey of well-known arguments - at least wellknown among game-theorists - that may also be helpful for climate policy analysts. Then, the subsequent section will provide an empirical assessment of the incentives to participate in several regional or sub-global climate blocs, and will compare their environmental effectiveness. A final session will summarise our results and discuss their policy implications.

\footnotetext{
${ }^{3}$ The groupings that are important for the WTO are those that abolish or reduce barriers to trade within the group. The WTO agreements recognize that regional arrangements and closer economic integration can benefit countries. It also recognizes that under some circumstances regional trading arrangements could hurt the trade interests of other countries. Normally, setting up a customs union or free trade area would violate the WTO's principle of equal treatment for all trading partners (“most-favoured-nation"). But GATT's Article 24 allows regional trading arrangements to be set up as a special exception, provided certain strict criteria are met. In particular, the arrangements should help trade flow more freely among the countries in the group without barriers being raised on trade with the outside world. In other words, regional integration should complement the multilateral trading system and not threaten it.
} 


\section{Regional and sub-global climate blocs. Lessons from coalition theory.}

The existing theoretical literature on coalition formation provides some reliable indications on the main features of the final equilibrium outcome of climate negotiations. If, as is often argued in the economic literature on international environmental agreements, a global agreement is unlikely to be attained (Cf. Carraro and Siniscalco, 1993; Barrett, 1994; recent surveys can be found in Barrett, 1997, 2002; Carraro and Galeotti, 2002), on the other hand, several small agreements are shown to be the equilibrium outcome of a coalition formation game with positive externalities (Cf. Bloch, 1997; Yi, 1997; Carraro, 2004), i.e. of a game that - like the climate change game - is characterised by free-riding incentives. Let us briefly review these latter results.

The strategic choice of players who decide whether or not to form a coalition with other players and, if they do, with which specific players to cooperate, has been the subject of recent research in game theory. ${ }^{4}$ These studies are based on a non-cooperative approach where binding commitments are excluded. This approach is particularly suitable for analysing the likely outcomes of future negotiations on climate change control, because no supra-national authority exists that can force countries to adopt policy measures to reduce their GHG emissions. Let us therefore examine the indications that the non-cooperative theory of coalition formation provides for the analysis of climate negotiations.

\footnotetext{
${ }^{4}$ Most papers have been presented at the annual workshops of the Coalition Theory Network (see www.feem.it/ctn). Some of them are published in Carraro (2003) and in Demange et al. (2005).
} 
The study of coalition formation poses three basic questions (Bloch 1996): (i) which coalitions will be formed ? (ii) how will the coalitional worth be divided among members ? (iii) how does the presence of other coalitions affect the incentives to cooperate? The traditional cooperative game theory (Cf. Aumann and Drèze, 1974) focuses on the second question - the division of the payoff between coalition members. The first question has been assumed away in most cooperative game theory and the third one is simply ignored, since the coalitional function cannot take into account externalities among coalitions.

These limitations have led to the emergence of a new strand of literature describing the formation of coalitions as a non-cooperative process. In the non-cooperative approach, a player's decision to join a coalition is often modelled as a two stage game. In the first stage, a player independently decides whether or not to join, by anticipating the consequence of his/her decision on the economic variables under control. In the second stage, he/she sets the value of these variables, given the coalition structure formed in the first stage. Under the simplifying assumption that the second stage equilibrium is unique for any coalition structure, the first stage game can be reduced to a partition function, which assigns a value to each coalition in a coalition structure as a function of the entire coalition structure. This enables us to capture the important effects of externalities across coalitions.

The theoretical literature on the non-cooperative coalition formation has shown that, even without any commitment to cooperation and even in the presence of positive spillovers (i.e. in the case in which the formation of a coalition by some players increases the payoff of the players outside the coalition, as for public good provision), countries may form a coalition.

The equilibrium coalition structure depends on several key assumptions, i.e. the membership rule, the order of moves, the players' conjectures, the slope of their reaction functions (Cf. Carraro and Marchiori, 2003). Nonetheless, 
some conclusions seem to be robust with respect to these assumptions and the related equilibrium concepts. For example, if a treaty is signed by many countries (i.e. a large coalition is formed) the amount of public good provided by the coalition (e.g. the amount of GHG abatement) is very close to the non-cooperative business-as-usual one (Barrett, 2002). As far as the goal of this paper is concerned, the most important conclusion is as follows. If countries are free to decide not only whether or not to sign a treaty but also which treaty (i.e. which coalition to join), there is generally more than one coalition at the equilibrium. For example, in the case of trade negotiations, there may be several trade blocs. In the case of environmental negotiations, several regional or sub-global climate agreements.

This conclusion can be found for example in Bloch (1995, 1996), Ray and Vohra (1997, 1999), Yi (1997, 2003) and Yi and Shin (1995). The models used in these studies analyse the formation of multiple coalitions by adopting different notions of stability. Bloch $(1995,1996)$ examines an infinite-horizon "coalition unanimity" game, in which a coalition forms if and only if all potential members agree to form the coalition. Ray and Vohra (1997) assume the "equilibrium binding agreement” rule, under which coalitions are allowed to break up into smaller sub-coalitions only. Yi and Shin (1995) investigate the "open membership" game, in which nonmembers can join an existing coalition even without the consensus of the existing members. Different membership rules lead to different predictions about stable coalition structures (Cf. Carraro and Marchiori, 2003). For example, the "open membership" rule is unlikely to support the grand coalition as an equilibrium outcome. The equilibrium coalition structure is generally very fragmented. By contrast, the "coalition unanimity” rule and the "equilibrium binding agreements" rule support more concentrated coalition structures at the equilibrium, but quite often not the grand coalition (Cf. Finus and Rundshagen, 2003). 
Despite these differences, at least two conclusions are common to all the aforementioned game-theory contributions. First, if countries can freely decide whether or not to cooperate, they usually divide themselves into two groups: a group of countries cooperate, whereas others free-ride. Secondly, at the equilibrium, the group of cooperators is split into several subgroups of cooperating countries, namely several coalitions form. These coalitions play non cooperatively against each other and against the free-riders.

The above results have been used by Carraro $(1998,1999)$ to argue that the Kyoto Protocol was unlikely to be signed by many countries and that the emergence of alternative climate blocs was highly likely. More recently, these same conclusions have been shown also by Bloch (2003), Finus and Rundshagen (2003), Yi (2003), Bretteville et al. (2004). All these papers use a game-theory approach. However, some indications that regional or subglobal climate blocs could be the appropriate way to address the difficulties emerging in climate negotiations can also be found in political science literature (see for example, Egenhofer and Legge, 2001; Egenhofer, Hager and Legge, 2001; Stewart and Wiener, 2003; Reinstein, 2004).

Game theory is still unable to identify the characteristics of the coalitions which could form at the equilibrium, because in theoretical models countries are usually assumed to be symmetric. By contrast, in actual climate negotiations, economic and environmental asymmetries play a very important role in defining a country's participation incentives. Therefore, game theory models cannot tell us whether coalitions are formed by similar or different countries, whether geographical proximity matters or whether economic factors are more relevant (e.g. whether climate coalitions will exploit abatement costs asymmetries). More specifically, game theory can hardly identify the climate blocs that are most likely to emerge out of future negotiations on climate change control. 
To address these latter issues, an applied game-theoretic analysis - where countries' asymmetric economic structures are explicitly modelled - is necessary, in order to appropriately identify the incentives that lead countries to an equilibrium, multi-coalition climate regime. This is what we aim to do in the following section.

\section{Regional and sub-global climate blocs. An applied game theory analysis.}

The analysis of the possible outcomes of the dynamic process that defines the incentives to participate in a climate agreement has been carried out by using a modified version of Nordhaus' RICE model (Cf. Nordhaus and Yang, 1996) in which endogenous and induced technical change are modelled. In our version of the model, called FEEM-RICE (Cf. Buonanno et al., 2002), technical change performs a twofold role: on the one hand, via increasing returns to scale, it yields endogenous growth; on the other hand, by affecting the emission/output ratio, it accounts for the adoption of cleaner and energy-saving technologies. ${ }^{5}$

In the model, six countries/regions (US, EU, Japan (JPN), former Soviet Union (FSU), China (CHN) and the rest of the world (ROW)) optimally set the intertemporal values of four strategic variables: investments, $R \& D$ expenditure, abatement effort and net demand for emission permits ${ }^{6}$. The countries play a two-stage game, whereby each of them decides independently in a first stage whether or not to join a coalition, by anticipating the consequence of its decision on the economic variables under

\footnotetext{
${ }^{5}$ The FEEM-RICE model has already been used in Buonanno, Carraro, Castelnuovo and Galeotti (2001), Buonanno, Carraro and Galeotti (2002), Buchner, Carraro and Cersosimo (2002), Buchner, Carraro, Cersosimo and Marchiori (2002) and in Buchner and Carraro (2004a). A brief description is contained in Buonanno, Carraro and Galeotti (2002).

${ }^{6}$ Note that, in all climate regimes, abatement is a strategic value which is optimally set at its welfare maximising level.
} 
control. In the second stage, each player sets the value of these variables, given the coalition structure formed in the first stage. When no coalition forms, each country/region maximises its own individual welfare, given the other countries' strategy. Countries which belong to the same coalition maximise their joint welfare. Given the interdependency of countries' decisions, the equilibrium value of the control variables is the solution for a dynamic open-loop Nash game. We apply thus an extension of the PANE equilibrium concept introduced by Eyckmans and Tulkens (2002). In addition, we adopt the "open membership” rule, implying that non-members can join an existing coalition even without the consensus of the existing members.

In addition to the model structure, two assumptions qualify our results ${ }^{7}$. First, all countries/regions which adhere to the Kyoto/Bonn agreement are assumed to meet their Kyoto target from 2010 onward. ${ }^{8}$ We therefore adopt the so-called "Kyoto forever" hypothesis (Manne and Richels, 1999). Our reference to the Kyoto/Bonn agreement is partly imprecise since, for the sake of brevity, we will at times call the "Kyoto protocol" or "Kyoto/Bonn agreement" a "Kyoto forever" scenario. Second, cooperating countries are assumed to adopt cost-effective environmental policies. In particular, costeffective market mechanisms (e.g. emission trading) are chosen over "command-and-control" measures in order to guarantee an efficient implementation of the environmental targets adopted within the coalition. Please note that Annex B countries that belong to a coalition and engage in

\footnotetext{
${ }^{7}$ Please note also that our analysis focuses only on CO2. There are other man-made greenhouse gases and the Kyoto Protocol takes some of them into account. Moreover, both the Bonn agreement and the subsequent Marrakech deal emphasise the role of sinks in meeting the Kyoto targets. As shown by several recent analyses (e.g. Manne and Richels, 2001; Jensen and Thelle, 2001), the inclusion of the other greenhouse gases and of sinks would further reduce mitigation costs .

${ }^{8}$ The use of the "Kyoto forever" hypothesis may be seen as a strong assumption. However, the CO2 concentration levels implicit in this assumption (if FEEM-RICE is a good description of the world) coincide with those in the A1B scenario (IPCC, 2001) which can be considered the "median" scenario among those currently proposed. We thus use the "Kyoto-forever" hypothesis not because it represents a realistic scenario, but as a benchmark with respect to which policy alternatives can be compared.
} 
emissions trading face thus their Kyoto targets, whereas China is assumed to agree to a $10 \%$ reduction of emissions with respect to the BAU scenario over the whole time horizon if it accepts to participate in a coalition (and in emissions trading). If various sub-global coalitions form, then they are assumed to behave independently, without a link between them (i.e., there is no trade between all regional blocs on a common market).

Using the FEEM-RICE model, we will analyse the incentives to move away from the present situation where the EU, Japan and Russia are committed to complying with their Kyoto targets and where the other countries/regions are free to determine their climate policy unilaterally. Therefore, our benchmark case, or business-as-usual scenario, to which we compare different potential climate regimes, is the coalition formed by the Annex B. us countries. A dynamic applied game-theoretic approach is used to identify a country’s optimal strategic behaviour, which will belong to an open-loop Nash equilibrium.

We will explore the economic and environmental implications of three possible two-bloc climate regimes. In the first climate regime, one coalition (bloc) is formed by the EU and Russia, the second one by Japan and China. In the second regime, the first bloc is formed by the EU and Japan, whereas the second one by the US and Russia. Finally, we will analyse the case in which the Annex $\mathrm{B}_{\text {-us }}$ bloc is complemented by a parallel bloc formed by the US and China. We will focus on changes of the main economic variables (welfare, as measured by discounted future consumption levels, R\&D expenditure, global CO2 emissions and abatement costs, for which an indicator is the equilibrium price in the permit market) with respect to the business as usual scenario.

Our focus is on post-2012 scenarios. We assume that a global agreement is only one of the possible outcomes of climate negotiations. Countries are also free to form regional or sub-global agreements. Therefore, we consider 
situations in which countries that now belong to the Kyoto coalition may decide, according to their own economic interests, to leave the Kyoto coalition and cooperate on GHG emission control with other countries/regions ${ }^{9}$. The time horizon over which climate policy is optimised is $2010-2100$.

We should stress that the focus of this paper is on economic incentives faced by countries, and that we thus adopt a positive approach without examining the stability of all potential agreements. There are several other political, cultural, environmental factors that could influence a country's decision to join a given climate coalition. These will not be addressed in this paper. However, the economic dimension of climate negotiations is a very important one (and has often been considered as the most important one in the US). Therefore, this paper can provide a relevant, albeit partial, contribution to the analysis of the future evolution of international climate policy.

\subsection{A two-bloc coalition structure: EU with Russia and Japan with}

\section{China}

The first case that we will analyse, using the FEEM-RICE model and a game-theoretic assessment of the optimal climate strategies in various countries/regions, is the one in which two blocs emerge out of climate negotiations. Let us assume that the US continue to adopt their own unilateral climate policy. What will the other countries do after 2012? One possibility is the formation of two regional climate blocs. One in Europe, formed by the EU and Russia, the other one in the Far-East, formed by Japan and China.

\footnotetext{
${ }^{9}$ Notice that the rest of the world (ROW) has been exempted from possible future climate commitments due to policy indications, which suggest that an inclusion of these countries is very unlikely in the next stage of climate negotiations.
} 
Russia has a strong interest in intensifying its relations with Europe, not only in order to improve its economic performance, but also to strengthen its political role within an enlarged, unified Europe. Cooperation on climate policy could demonstrate that Russia is indeed willing and prepared to bear responsibility and would thus be an important step in the direction of Western Europe. The recent ratification of the Kyoto Protocol by the Putin administration confirms this political trend. Therefore, a scenario is which the EU and the FSU closely cooperate on climate seems to be likely, whereas there is increasing emphasis in Japan in favour of regional economic cooperation in East Asia and above all with China. Therefore, as part of its efforts to foster cooperation with China, Japan could also propose a deal concerning GHG emission reduction.

The cooperation between China and Japan seems to be plausible because it would quite plausibly enhance the role of their geographical area and thus give the two countries stronger political weight. In addition, this cooperation could enable Japan to reduce its high abatement costs, China to improve its environmental performance and at the same time to profit from selling permits in the bilateral emission trading market. Since China officially demonstrates its "strong expectations of advanced Japanese environmental protection technologies to combat its own environmental problems" (The Japan Times, Jan. 26 , 2002), a "win-win case” could be established if China could improve its environmental protection with Japanese assistance, while Japan could reach its Kyoto emission reduction target at a lower cost by cooperating with China.

Figure 1 illustrates the main economic and environmental consequences of a regime based on two regional blocs: EU and FSU on the one hand, JPN and China on the other one. From Figure 1, it is clear that, with respect to the Annex $B_{\text {-us }}$ case, China and FSU are the two losers. China because it moves from free-riding to climate change cooperation, even though its abatement 
target is close to what it would be in a business-as-usual scenario. ${ }^{10}$ The welfare loss of the FSU is even stronger because Japan no longer buys permits from the FSU. Therefore, the permit price in the bilateral market with the EU becomes very low with respect to the price when the Annex B. us coalition forms (-25.2\%). As a consequence, the EU reduces its abatement costs through a lower permit price induced by the reduced demand compared to the benchmark case.

Japan is the main winner in this scenario. Japan gains because it can buy cheaper permits from China, since the permit price falls in comparison to the "Kyoto forever" regime where the Annex B-us coalition forms (in particular, the permit price in this market is $86.1 \%$ lower than in the benchmark case).

Figure 1: A climate regime with two blocs: 1) Japan and CHN; 2) EU and FSU.

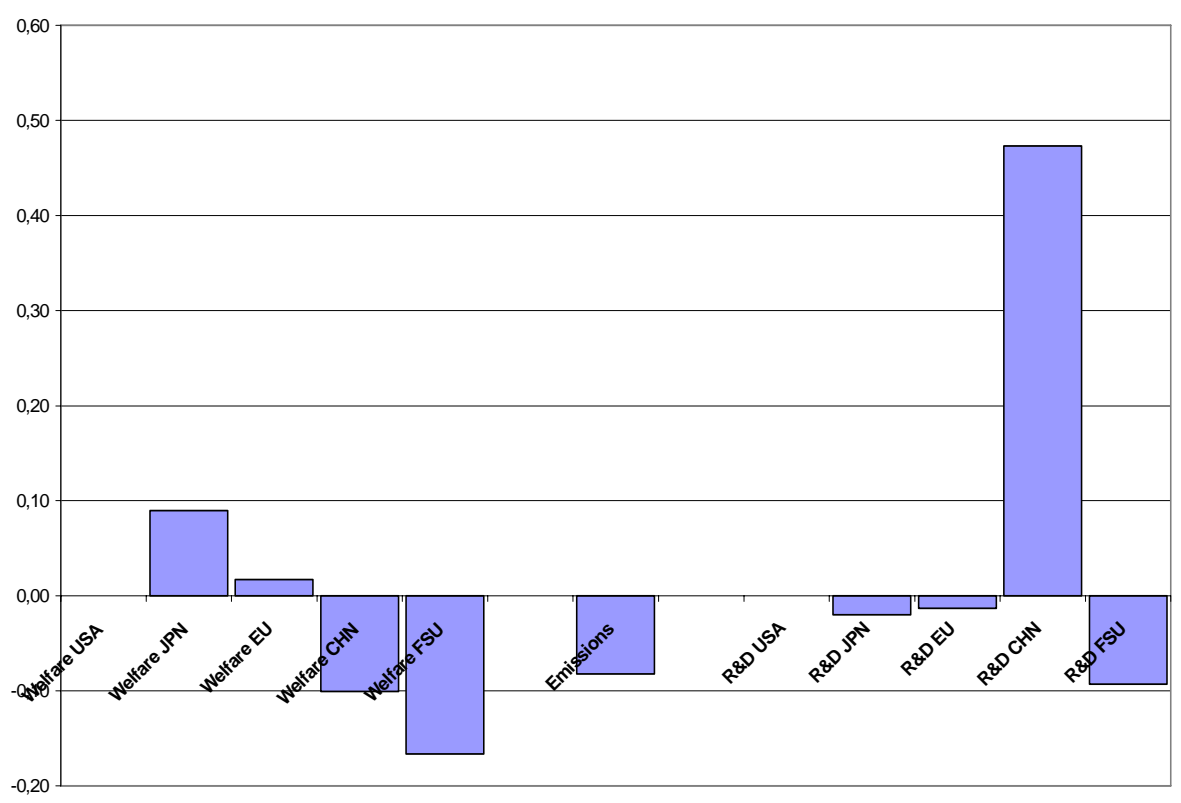

\footnotetext{
${ }^{10}$ We assume that China agrees to a $10 \%$ reduction of emissions with respect to the BAU scenario over the whole time horizon.
} 
With respect to the Annex $\mathrm{B}_{\text {-us }}$ case, China increases its strategic $\mathrm{R} \& \mathrm{D}$ investments in order to have more supply of permits at its disposal, since a higher supply of permits implies an increase in their benefits from selling the permits on the emission market. Instead, the FSU reduces $R \& D$ investments because the profitability of the bilateral permit market with the $\mathrm{EU}$ is much lower than the profitability of the permit market where Japan is also a buyer. Total emissions become smaller because of the increased abatement in China.

Therefore, when compared to our benchmark case, this two-blocs climate regime is profitable both to the EU and to Japan, who could therefore implement some compensation schemes to offset the losses incurred by China and above all by the FSU. However, when compared with the coalition formed by Annex $\mathrm{B}_{\text {-US }}+$ China, the two bloc regime does not yield a positive welfare change for any of the cooperating countries. ${ }^{11}$ Therefore, on the basis of economic incentives, the two-bloc climate regime just analysed does not seem to be likely. However, this regime is more environmentally effective than both the Annex $\mathrm{B}_{\text {-us }}+$ China regime and the “Kyoto forever” one.

The above analysis has not yet taken into account the role of the US. Is the US going to remain "stand alone" and to implement a domestic climate policy, which is likely to only achieve their non- cooperative emission abatement levels? Or will the US counter propose bilateral or trilateral deals with some other countries/regions in order to reduce their abatement costs and increase their environmental effectiveness?

At the moment, the US is outside the Kyoto framework and has announced its alternative Climate Change Initiative. Even though the most obvious immediate US reaction lies in a domestic abatement program, other US

\footnotetext{
${ }^{11}$ The economic implications of the coalition formed by the Annex B-us countries and by China are analysed in Buchner and Carraro (2004b).
} 
moves are likely, and these may induce the emergence of other types of coalitions. As soon as the US realises that a large amount of emission abatement must be undertaken, they will also realise that these emission reductions are too costly if undertaken through domestic measures only. Already now, US industrial groups fear they may not qualify for incentives that Kyoto countries use to promote emission reductions (The Washington Times, Jan. $24^{\text {th }}$, 2002). Moreover, the US have significant economic and strategic as well as environmental interests in joining the international cooperative effort to control climate change, since they cannot afford to remain on the sidelines while others design a global climate regime (Stewart and Wiener, 2003).

As recently reported in the international press, a proposal aims at establishing a scheme based on a cap on emission levels and awards for permits under the NAFTA. This alternative would imply that the US, Canada and Mexico were participants in a cross-border trading scheme (Financial Times, Dec. $4^{\text {th }}$ and $13^{\text {th }}, 2001$ ). The establishment of a regional trading system under NAFTA has above all been urged by private sector advisers $^{12}$.

Other signs of an active international US role are the "US-Australia Climate Action Partnership”, an initiative consisting of various programs aimed at improving scientific cooperation in areas including climate change science, reduced emissions strategies and engagement with business on technology to reduce GHG emissions (News.com.au, July $2^{\text {nd }}, 2002$, CO2e.com, July $\left.7^{\text {th }}, 2002\right)$. Or a similar partnership between the US and Japan, aimed at promoting joint projects and exchanging opinions on various measures to

\footnotetext{
${ }^{12}$ Also in Canada, which is still partner in the Umbrella Group, industry is asking for clarification regarding the economic consequences of implementing the Kyoto Protocol without the US. The Canadian government recognises the difficulties that arise from the linked nature of American and Canadian economies, but is still supportive to the agreement (the Kyoto Protocol was ratified by Canada in December 2001).
} 
prevent global warming (CO2e.com, April $5^{\text {th }}$, 2002) and a comparable USIndia technology cooperation project.

A further step in the US strategy could thus consist in offering a partnership to large emission permit suppliers, as e.g. the FSU or China. In order to improve its performance in the emission market, the US could offer the FSU or China better conditions than the ones offered by the EU and Japan. Let us therefore analyse these two scenarios.

\subsection{A second two-bloc coalition structure: US with Russia and EU with} Japan

What would be the consequences of a climate regime in which the US and the FSU cooperate ${ }^{13}$ without the EU and Japan, while these two countries remain committed to their Kyoto obligations?

As shown by Figure 2, this two-bloc climate regime is certainly environmentally effective - emissions decrease by $10 \%$ with respect to the benchmark - but it is not likely to emerge, because total welfare of all cooperating countries becomes lower. Only China improves its welfare, because more abatement is undertaken at the world level. However, China's welfare in this two bloc regime is again lower than its welfare in the coalition formed by Annex B-us + China (Cf. Buchner and Carraro, 2004b).

The reason for the reduced welfare in the EU and Japan is fairly evident. Their abatement costs largely increase because they can no longer exploit the lower abatement costs in the FSU (the permit price in the EU-Japan market increases by $220.6 \%$ with respect to the benchmark "Kyoto forever" case).

\footnotetext{
${ }^{13}$ The United States and Russia said on January $17^{\text {th }}$, 2003 that they would seek a common approach to battling global warming. The first meeting of the Russian-American intergovernmental workgroup looking into climatic changes took place in Moscow, in April 2003 (Agence France-Presse, Jan. 17 ${ }^{\mathrm{th}}$, 2003).
} 
The reason for the reduced welfare in the US depends on our choice of the benchmark. We are comparing a situation in which the US cooperates with the FSU with a situation in which it free-rides (the Annex B-us coalition). Therefore, even though it can take advantage from the FSU's "hot air", its costs obviously increase because it increases its abatement effort with respect to the free-riding abatement effort. For the same reason, US welfare is also lower if compared with its welfare when the coalition (Annex B-us + China) forms.

Finally, the FSU's welfare also decreases because marginal abatement costs in the US are lower than in Japan and the EU. Therefore, the permit price in the US-FSU market is lower (-25.2\%) than in the EU-Japan-FSU market. As a consequence, the FSU reduces its revenue from selling permits. In addition, the incentive to undertake strategic $\mathrm{R} \& \mathrm{D}$ is lower than in the benchmark case. Hence, R\&D in the FSU is lower, thus lowering the supply of permits. R\&D is instead much higher in the US, which is faced a real incentive to abate emissions at low cost.

Figure 2: A second climate regime with two blocs: 1) US and FSU; 2) EU and Japan.

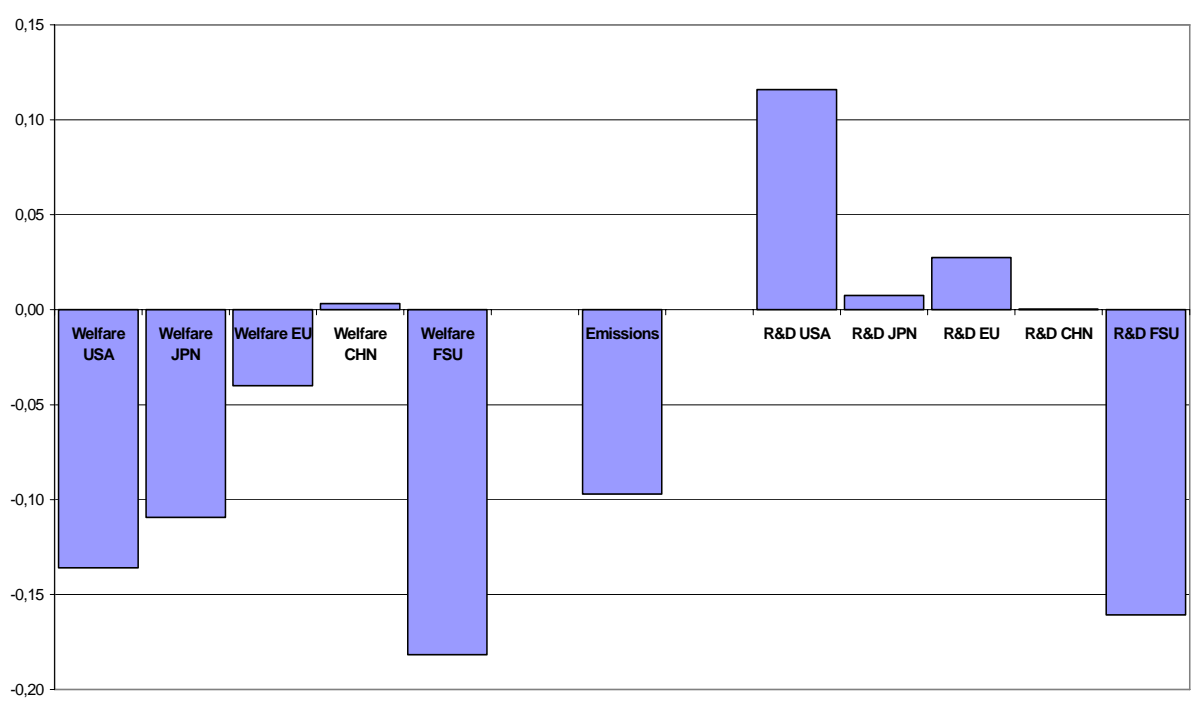


Summing up, this climate regime is unlikely to emerge because of the lack of economic incentives, even though the cooperation within the two blocs is more environmentally effective than cooperation within the "Kyoto forever" coalition.

Let us therefore explore a third scenario, where again a two bloc climate regime forms. This scenario originates from two basic facts: (i) it is unlikely that a US strategy could break the Annex B-us bloc, due both to political reasons and because of the lack of economic incentives just described; (ii) in the US, the involvement of developing countries in a cooperative climate regime is seen as crucial to achieving long term goals. Therefore, in order to reduce its abatement costs and increase its domestic political credibility, the US could negotiate an agreement with China, thus giving rise to an emissions trading market where the equilibrium permit price would be low. The climate regime would then be formed by the following two blocs: US and China on the one hand, and EU, Japan and FSU on the other.

\subsection{A third two-bloc coalition structure: US with China and EU with}

\section{Russia and Japan}

There is some evidence that this regime may not be unrealistic. China's decision to ratify the Kyoto Protocol demonstrates that the country is aware that benefits from ratification could be high because China is the largest permit seller. Chinese officials emphasise that the government will voluntarily try to restrict the growth of $\mathrm{CO} 2$ emissions, but is strictly opposing binding GHG reduction targets (The Japan Times, Jan. 26 ${ }^{\text {th }}$, 2002). ${ }^{14}$

\footnotetext{
${ }^{14}$ However, in the longer term, China will have to cope with its role of second-largest CO2 emitter in the world. The first signs that China is recognising these political reasons are clear. The ratification of the Kyoto protocol in its actual form could therefore be interpreted more as a long-term commitment to emission control than as a short run strategy to reap the benefits on the emission trading market.
} 
Without binding commitments or with very mild abatement targets and given the consequent high amount of permits which can be supplied, China is a very attractive partner in climate change control activities. This is why the US could convince China to cooperate under a joint climate pact. In this way, the US could achieve two goals: (i) satisfy domestic political requirements by involving developing countries in their climate strategy; (ii) reap high benefits from a large joint emissions market (the US and China together account for more than one-third of the world-wide $\mathrm{CO} 2$ emissions and this share is becoming larger and larger). In particular, the US could drastically decrease their abatement costs through emission trading and China could profit from selling a large amount of permits.

What would then be the main consequences of a two bloc climate regime with a first bloc formed by the EU, Japan and the FSU (the Kyoto coalition) and a second bloc formed by the US and China? Some of these consequences are shown in Figure 3.

First of all, it is clear that both the US and CHN lose with respect to the case in which they free-ride. However, the loss for the US is small and could be largely compensated by some ancillary benefits from GHG emission abatement that are not taken into account in our model.

The loss for China is also small - and even smaller when compared to the regime in which the coalition (Annex B-us + China) forms - and ancillary benefits, both on the environmental and economic side, could be large. Note that, as discussed in the next section, this climate regime is the one most preferred by both the US and China when they do not free-ride. Namely, it is the most preferred among those in which they undertake some cooperative emission abatement.

The inclusion of China in a coalition with the US is slightly beneficial for the Kyoto climate bloc consisting of the European Union, Japan and the 
FSU, because of the enhanced environmental effectiveness of this two-bloc regime. Indeed, GHG emissions are almost $20 \%$ lower than in the benchmark case, and also lower with respect to total emissions in the climate regime in which the coalition (Annex $\mathrm{B}_{\text {-Us }}+$ China) forms. However, the coalition (Annex $\mathrm{B}_{\text {-us }}+$ China) is the most preferred by the EU and Japan, because the absence of China from the coalition increases marginal abatement costs and thus induces welfare losses for the EU and Japan.

Figure 3: A third climate regime with two blocs: 1) US and CHN; 2)

\section{EU, FSU and Japan}

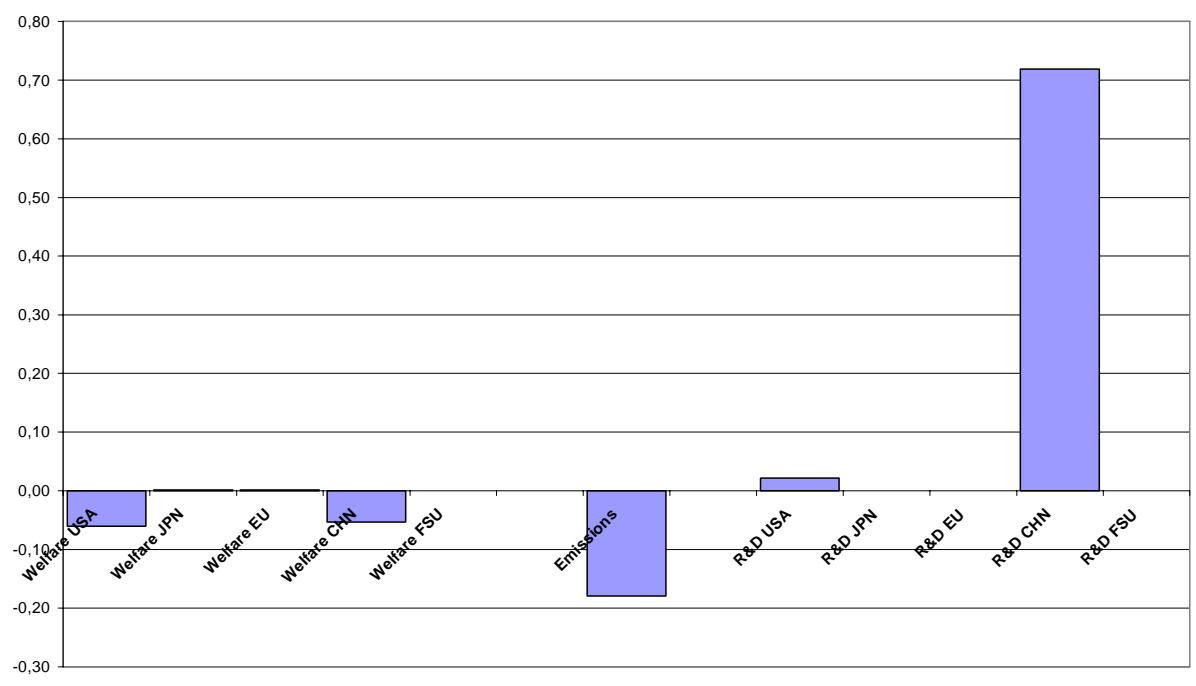

This two-bloc climate regime is characterised again by a large expansion of China’s R\&D investments. China over-invests in R\&D to increase its sales in the bilateral emission trading market. The segmentation of the trading market also explains why R\&D investments within the benchmark Annex B. us coalition do not change. However, if the comparison is made with the coalition (Annex $B_{\text {-us }}+$ China), then it can be seen that R\&D investments in this climate regime are higher for all Annex $B_{\text {-us }}$ countries. The reason is again the larger marginal abatement costs when China is not a seller in the 
permit market. This induces higher investments in $R \& D$ in the EU and Japan and also strategic R\&D investments in the FSU, which will find it optimal to increase its supply of permits.

The next section will provide a synthesis of our results by comparing different regimes not only with respect to the benchmark climate coalition formed by the Annex $\mathrm{B}_{\text {-us }}$ countries, but also by cross-comparing all different regimes in terms of domestic welfare and global emissions. This comparison will enable us both to assess the consistency of our results with the game-theory predictions described in Section 2 and to draw some policy conclusions.

\section{Participation incentives in a bottom-up regime: some policy implications.}

In the previous sections, three two-bloc climate regimes have been identified as possible evolutions of the present situation in which the Annex B-us countries - EU, FSU and Japan - cooperate to reduce GHG emissions. Costs and benefits of a move from this benchmark regime to a new one have been discussed.

This section attempts to draw some policy lessons from the above analyses. To achieve this goal, we need to complement the economic and political analysis of the previous sections with a comparison across all potential new climate regimes $^{15}$. In this section, for reasons of space, we focus this comparison on two dimensions: domestic welfare and global emissions. Namely, we plan to identify each country's most preferred regime and to compare it with the socially optimal regime. In addition, the most

\footnotetext{
${ }^{15}$ Given the policy indications, which suggest that an inclusion of the least-developed countries is very unlikely in the next stage of climate negotiations, we have decided to exempt the rest of the world (ROW) from potential short- to medium term emission reduction commitments.
} 
environmentally effective climate regime will also be considered as a possible target that policy could achieve.

Our results are summarised by Tables $1 \mathrm{a}, 1 \mathrm{~b}$ and 2 . Tables $1 \mathrm{a}, 1 \mathrm{~b}$ show the ranking of climate coalition structures according to domestic welfare. Table 2 shows the ranking of climate regimes according to global welfare and global emissions. These tables provide information that could enable us to identify the most likely behaviour of countries in future climate negotiations (at least to the extent that economic incentives affect climate negotiations).

Let us first focus on the US. The two most preferred coalition structures are the ones in which the US is not involved in any climate coalition (see Table 1a). Note that the US's most preferred regime is the present Annex B-us coalition. However, the US's most preferred regime when it participates in a climate coalition is the one in which the US cooperates (and trades) with China, whilst a second cooperative bloc is formed by the Annex B-us coalition, i.e. the US prefers the coalition structure [(JPN, EU, FSU), (USA, CHN)].

The ranking of climate coalition structures for the two main industrialised countries involved in the "Kyoto forever" regimes indicates some similarities. Both the EU and Japan rank the present "Kyoto forever" coalition very low, thus suggesting that a post-2012 change is likely. And both rank cooperation with China quite high. Indeed, the coalition (JPN, EU, CHN, FSU) is the EU's most preferred regime, while Japan ranks first the coalition structure consisting of two blocs, the Asian bloc (JPN and $\mathrm{CHN}$ ) on the one hand and the European bloc (EU plus FSU) on the other. In both cases, the EU and Japan can profit from either a large emission permit market or at least the presence of an important permit supplier, which implies a low permit price and thus low abatement costs. The worst regime for the EU (and for Japan) is the one in which the EU and Japan form a coalition without having any large permit supplier at their disposal. 


\begin{tabular}{|l|l|l|}
\hline USA & JPN & EU \\
\hline (JPN, EU, FSU) & (EU, FSU) & (JPN, EU, CHN, FSU) \\
\hline (JPN, CHN) \& (EU, FSU) & (JPN, CHN) \& (EU, FSU) & (USA, JPN, EU, CHN, FSU) \\
\hline (JPN, EU) & (JPN, EU, CHN, FSU) & (JPN,CHN) \& (EU, FSU) \\
\hline EU, FSU) & (USA, JPN, EU, CHN, FSU) & (EU, FSU) \\
\hline $\begin{array}{l}\text { (JPN, EU, CHN, FSU) } \\
\text { CHN) EU, FSU) \& (USA, }\end{array}$ & $\begin{array}{l}\text { (JPN, EU, FSU) \& (USA, } \\
\text { (JPN, EU, FSU) \& (USA, } \\
\text { CHN) }\end{array}$ \\
\hline (USA, JPN, EU, CHN, FSU) & (USA, JPN, EU, FSU) & (UPN, EU, FSU) \\
\hline (JPN, EU) \& (USA, FSU) & (JPN, EU) \& (USA, FSU) & (JPN, EU) \& (USA, FSU) \\
\hline (USA, JPN, EU, FSU) & (JPN, EU) & (JPN, EU) \\
\hline
\end{tabular}

Table 1a. The ranking of climate regimes according to domestic total welfare: US, JPN and EU

Note that the coalition structure [(JPN, EU, FSU), (USA, CHN)], i.e. the climate regime in which the US and China cooperate within one bloc, whilst EU, FSU and Japan cooperate within a second bloc, is ranked fifth both by the EU and by Japan. However, there are also some differences in the preferences of the EU and Japan. In particular, large coalitions are more preferred by the EU than by Japan.

Let us analyse the preferences of the less developed countries, China and the FSU. China acts as a rational free-rider. Its preferred regime is the two-bloc regime in which the EU cooperates with Japan and the US with Russia, and its second-best option is a regime in which China free-rides. China's most preferred regime when it participates in a climate coalition is the one in which China cooperates (and trades) with the US, whilst a second cooperative bloc is formed by the Annex B-us coalition. The possibility of an Asian bloc appears to restrict its potential advantage with respect to gains from the emission market. 
Finally, the FSU is penalised by China's participation in a climate regime for the reasons explained in the previous section. Therefore, the FSU would like to avoid coalitions in which China also participates. The FSU's most preferred regime is the Annex $B_{\text {-us }}$ coalition, where China is not involved and Russia therefore represents the only permit seller.

\begin{tabular}{|l|l|}
\hline CHN & FSU \\
\hline (JPN, EU) \& (USA, FSU) & (JPN, EU) \\
\hline (USA, JPN, EU, FSU) & (USA, JPN, EU, FSU) \\
\hline (JPN, EU, FSU) & (JPN, EU, FSU) \\
\hline (JPN, EU) & (JPN, EU, FSU) \& (USA, CHN) \\
\hline (EU, FSU) & (JPN, EU, CHN, FSU) \\
\hline (JPN, EU, FSU) \& (USA, CHN) & (EU, FSU) \\
\hline (USA, JPN, EU, CHN, FSU) & $($ JPN, CHN) \& (EU, FSU) \\
\hline (JPN, EU, CHN, FSU) & $($ JPN, EU) \& (USA, FSU) \\
\hline (JPN, CHN) \& (EU, FSU) & (USA, JPN, EU, CHN, FSU) \\
\hline
\end{tabular}

Table 1b. The ranking of climate regimes according to domestic total welfare: CHN and FSU

What are the policy lessons that can be derived from Tables 1a and 1b? As seen above, US and China have a strong incentive to free-ride, namely to set their environmental policy unilaterally, thus profiting from the abatement levels set for the Kyoto coalition countries. In particular, the Annex B-us coalition is the US's most preferred regime and has been ranked third by

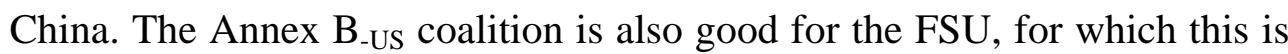
the second-best outcome when it decides not to free-ride.

EU and Japan have a strong incentive to maintain cooperation with a large permit seller, e.g. at least with the FSU. Indeed, the worst coalition structures for the EU and for Japan are the ones in which the EU and Japan form a coalition without either China or the FSU. 
In short, the climate coalition structure where only the EU, Japan and the FSU cooperate is fairly stable in terms of economic incentives, but highly ineffective from an environmental viewpoint, as is demonstrated by Table 2 . Paradoxically, this regime is not welcome by the EU and Japan, but is among the most preferred ones by the other countries.

What could be an alternative climate regime with adequate economic incentives for the participating countries/regions? It is clear the Russia does not like to cooperate with China, because of the losses that it would suffer in the permit market. China would like to free ride, but if it cooperates, it prefers the coalition structure [(JPN, EU, FSU), (USA, CHN)]. Likewise for the US. The EU would prefer a large coalition, whereas Japan likes a regional two-bloc coalition (when it does not free ride).

Therefore, if for some environmental, economic or political reasons, the US and China decide to cooperate to control their GHG emissions, they may sign a bilateral agreement rather than joining a large global coalition. This situation, which corresponds to the coalition structure [(JPN, EU, FSU), (USA, CHN)], slightly increases welfare in the EU, Japan and the FSU, at least with respect to the present Kyoto coalition (see Figure 3). Therefore, the Annex $B_{\text {-us }}$ countries may accept a two bloc regime, where the US and CHN cooperate on emission abatement and trade permits in a bilateral permit market. The economic loss for the US and CHN would be small with respect to the situation in which they free-ride, but the global environmental benefits would be large. Even though this is not the most preferred outcome for any country, it is the outcome which is likely to be the most attractive or at least the one which raises the smallest opposition.

The above conclusion is based on a decentralised analysis of each country's incentives to join a climate coalition. However, it would be important to assess what a central planner would do when his/her goal is the 
maximisation of global welfare. The answer is provided by Table 2, which shows that global welfare - which includes welfare of free-riders - is maximised when the coalition structure [(JPN, EU, CHN, FSU), USA] forms ${ }^{16}$. Second is the coalition structure [(JPN, CHN), (EU, FSU), USA], whereas the climate regime where the US cooperates with China and the Annex $B_{- \text {-Us }}$ forms as a second bloc, i.e. [(JPN, EU, FSU), (USA, CHN)], is only sixth. Notice, that global welfare seems to be maximised when the US does not belong to a climate coalition, which suggests that an unconstrained growth of the US economy may be beneficial to the world economy, despite the damage to the environment.

\begin{tabular}{|c|c|}
\hline Global GHG Emissions & Global Welfare \\
\hline (USA, JPN, EU, CHN, FSU) & (JPN, EU, CHN, FSU) \\
\hline (JPN, EU, FSU) \& (USA, CHN) & (JPN, CHN) \& (EU, FSU) \\
\hline (JPN, EU) \& (USA, FSU) & (EU, FSU) \\
\hline (USA, JPN, EU, FSU) & (JPN, EU, FSU) \\
\hline (JPN, CHN) \& (EU, FSU) & (USA, JPN, EU, CHN, FSU) \\
\hline (JPN, EU, FSU) & (JPN, EU, FSU) \& (USA, CHN) \\
\hline (JPN, EU, CHN, FSU) & (JPN, EU) \\
\hline (EU, FSU) & (USA, JPN, EU, FSU) \\
\hline (JPN, EU) & \\
\hline
\end{tabular}

Table 2. The ranking of climate regimes according to global welfare and global GHG emissions

Table 2 also illustrates that the two-bloc climate regime [(JPN, EU, FSU), (USA, CHN)] would provide the second largest possible benefits for the

\footnotetext{
${ }^{16}$ The fact that the grand coalition does not appear first in the ranking of global welfare is due to the exemption of ROW from the climate coalitions considered as possible in the near future.
} 
environment, without inducing high economic costs in the cooperating countries.

\section{Conclusion}

The conclusion emerging from the above analysis can be summarised as follows. A move from the current climate regime is not likely, at least in the short-run. The US - which presently does not participate in the Kyoto Protocol - is more likely to adopt unilateral policies than to join a coalition to control GHG emissions. However, it is unlikely that, at least in the medium term, the US continues to reject any form of cooperation on climate change control. If the US decides to cooperate, the climate regime which is least opposed (in terms of net economic benefits) by the negotiating countries is the one in which China and the US cooperate bilaterally and the Annex B-us countries form a parallel coalition.

Of course, the above findings must be taken cautiously. First, because they are based only on the analysis of economic incentives, whereas political decisions could be taken on the basis of other types of incentives. Second, because we did not account for the link between climate negotiations and other international negotiation processes (e.g. on crime, trade, terrorism, technology, etc.). Third, because the FEEM-RICE model used in this study is a simplified representation of the world economic system, even though it captures the main economic mechanisms and the related incentive schemes.

Nonetheless, the results derived from the empirical analysis proposed in this paper are quite consistent with suggestions and results proposed in gametheory literature (where countries' asymmetries are usually neglected). This suggests that the analysis in this paper is likely to capture the relevant economic incentives and may therefore serve to provide indications on the prospective future evolution of climate coalitions. 


\section{References}

Aldy, J.E., Barrett, S. and Stavins, R.N. (2003), Thirteen Plus One: A Comparison of Global Climate Policy Architectures, Climate Policy, 3(4), 373-397.

Aldy, J.E., Ashton, J., Baron, R., Bodansky, D., Charnovitz, S., Diringer, E., Heller, T.C., Pershing, J., Shukla, P.R., Tubiana, L., Tudela, F. and Wang, X. (2003), Beyond Kyoto: Advancing the International Effort Against Climate Change, Pew Center on Global Climate Change.

Agence France-Presse, Russia, US vow to join battle on global warming, January $\quad 17^{\text {th }}$, $2003 \quad$ Online at http://www.spacedaily.com/2003/030117170903.zg9k9g74.html

Aumann, R. and J. Drèze (1974), Cooperative Games with Coalition Structures, International Journal of Game Theory, 3, 217-37.

Baldwin, R. (1993), A Domino Theory of Regionalism. NBER Working Paper No. 4465.

Barrett, S. (1994) Self-Enforcing International Environmental Agreements, Oxford Economic Papers, 46, 878-894.

Barrett, S. (1997) Towards a Theory of International Cooperation, in C. Carraro and D. Siniscalco, eds., New Directions in the Economic Theory of the Environment, Cambridge University Press, Cambridge.

Barrett, S. (2001), Towards a Better Climate Treaty, Policy Matters 01-29, Washington, DC: AEI-Brookings Joint Center for Regulatory Studies.

Barrett, S. (2002), Environment and Statecraft. Oxford: Oxford University Press.

Barrett, S., and R.N. Stavins (2003), Increasing Participation and Compliance in International Climate Change Agreements, International Environmental Agreements: Politics, Law and Economics 3 (2003): 349-376.

Baumert, K., Blanchard, O., Llosa, S. and Perkaus, J. (eds.) (2002), Building on the Kyoto Protocol: Options for Protecting the Climate, World Resource Institute (WRI).

Bloch, F. (1995) Endogenous Structures of Associations in Oligopolies, RAND Journal of Economics, 26, 537-556.

Bloch, F. (1996) Sequential Formation of Coalitions in Games with Externalities and Fixed Payoff Division, Games and Economic Behavior, 14, 90-123.

Bloch, F. (1997) Non-Cooperative Models of Coalition Formation in Games with Spillovers, in C. Carraro and D. Siniscalco, eds., New Directions in the Economic Theory of the Environment, Cambridge University Press, Cambridge, ch. 10, 311-352. 
Bloch, F. (2003), Noncooperative Models of Coalition Formation in Games with Spillovers, in C. Carraro (ed.), The Endogenous Formation of Economic Coalitions, E.Elgar, Cheltenham.

Bloch, F. and H. Ferrer (1999), Trade Fragmentation and Coordination in Bilateral Oligopolies. CORE Discussion Paper No. 9908.

Bodansky, D. (2004), International Climate Efforts Beyond 2012: A Survey of Approaches, prepared for the Pew Center on Global Climate Change, with contributions from Sophie Chou and Christie JorgeTresolini.

Bond E. and C. Syropoulos (1996), The Size of Trading Blocs. Market Power and World Welfare Effects. Journal of International Economics, Vol. 40 (1996), 417-37.

Botteon, M. and C. Carraro (1997), Burden-Sharing and Coalition Stability in Environmental Negotiations with Asymmetric Countries, in C. Carraro, ed., International Environmental Agreements: Strategic Policy Issues, E. Elgar, Cheltenham.

Boonekamp, C. (2003), The Changing Landscape of RTAs, WTO Secretariat, Trade Policies Review Division, prepared for the Seminar on "Regional Trade Agreements and the WTO", WTO Secretariat, Geneva, 14 November 2003.

Bretteville, C., Hovi, J. and F.C. Menz (2004), Regional versus Global Cooperation for Climate Control, mimeo, Cicero, Oslo, Norway.

Buchner, B. and C. Carraro (2004a), Economic and Environmental Effectiveness of a Technology-based Climate Regime, FEEM Working Paper 61.04, FEEM, Milan.

Buchner, B. and C. Carraro (2004b), US, China and the Economics of Climate Negotiations, mimeo, FEEM, Milan.

Buchner, B., C. Carraro and I. Cersosimo (2002), Economic Consequences of the U.S. Withdrawal from the Kyoto/Bonn Protocol. Climate Policy 2 (2002), 273-292.

Buchner, B., C. Carraro, I. Cersosimo and C. Marchiori (2002), Back to Kyoto? US Participation and the Linkage between R\&D and Climate Cooperation. CESifo Working Paper No. 688 (8) and FEEM Working Paper 15.02, Milan. Forthcoming in A. Haurie and L. Viguier, eds., Coupling Climate and Economic Dynamics, Kluwer Academic Publishers, Dordrecht.

Buonanno, P., Carraro, C., Castelnuovo, E. and M. Galeotti (2001), Emission Trading Restrictions with Endogenous Technological Change. International Environmental Agreements. Law Politics Economics, 1 (3), 397-395.

Buonanno, P., C. Carraro, and M. Galeotti (2002), Endogenous Induced Technical Change and the Costs of Kyoto, Resource and Energy Economics, 524, 11-35. 
Casella, A. (1995), Large Countries, Small Countries and the Enlargement of Trade Blocs. NBER Working Paper No. 5365.

Carraro, C. (1998), Beyond Kyoto: A Game Theoretic Perspective, in the Proceedings of the OECD Workshop on "Climate Change and Economic Modelling. Background Analysis for the Kyoto Protocol”, Paris, 17-18.9, 1998.

Carraro, C. (1999), The Structure of International Agreements on Climate Change, in C. Carraro, ed., International Environmental Agreements on Climate Change, Kluwer Academic Pub.: Dordrecht.

Carraro, C., ed. (2003), The Endogenous Formation of Economic Coalitions, E.Elgar, Cheltenham.

Carraro, C. (2004), Institution Design for Managing Global Commons, forthcoming in G. Demange, D. Ray and M. Wooders, eds., Group Formation in Economics. Networks, Clubs and Coalitions, Cambridge University Press, Cambridge.

Carraro, C. and D. Siniscalco (1993), Strategies for the International Protection of the Environment, Journal of Public Economics, 52, 309-328.

Carraro, C. and M. Galeotti (2002), The Future Evolution of the Kyoto Protocol. Costs, Benefits, Incentives to Ratification and New International Regimes, in C. Carraro and C. Egenhofer, eds., Firms, Governments and Climate Policy: Incentive-Based Policies for LongTerm Climate Change, Edward Elgar, Cheltenham, 2002.

Carraro, C. and C. Marchiori (2003), Stable Coalitions, in C. Carraro, ed., The Endogenous Formation of Economic Coalitions, E.Elgar, Cheltenham.

CO2e.com, Japan, U.S. agree on 15 steps on global warming: Jiji Press, April $5^{\text {th }}, 2002$. Online at www.co2e.com

CO2e.com, Australia, US sign rebel pact on carbon: Australasian Business Intelligence, July $7^{\text {th }}$, 2002. Online at www.co2e.com

CNRS/LEPII-EPE, RIVM/MNP, ICCS-NTUA and CES-KUL (2003), Greenhouse Gas Reduction Pathways in the UNFCCC Process Up To 2025; Policymakers Summary, Study prepared for DG Environment, downloadable at http://europe.eu.int/comm/environment/climat/studies.htm

Demange, G., Ray, D., and M. Wooders, eds. (2005), Group Formation in Economics. Networks, Clubs and Coalitions, Cambridge University Press, Cambridge.

Egenhofer, C. and T. Legge (2001), After Marrakech: The Regionalisation of the Kyoto Protocol. CEPS Commentary.

Egenhofer, C., W. Hager and T. Legge (2001), Defining Europe's Near Abroad in Climate Change: A Russian-EU Alliance - Sub-global 
Bargaining to Further International Environmental Agreements. CEPS Discussion Paper.

Eyckmans, J. and H. Tulkens (2002), Simulating Coalitionally Stable Burden Sharing Agreements for the Climate Change Problem, CORE Discussion Paper 9926 and CLIMNEG Working Paper 18, Université Catholique de Louvain, Belgium.

Financial Times, North America to plan for trading in emissions, December $4^{\text {th }}$, 2001. Online at http://www.FT.com/

Financial Times, North America ponders Kyoto alternative, December $13^{\text {th }}$, 2001. Online at http://www.FT.com/

Finus, M. and B. Rundshagen (2003), Endogenous Coalition Formation in Global Pollution, in C. Carraro, ed., The Endogenous Formation of Economic Coalitions, E.Elgar, Cheltenham.

IPCC (2001), Third Assessment Report, Cambridge University Press, Cambridge.

Jensen, J. and M.H. Thelle (2001), What are the gains from a multi-gas strategy? FEEM Working Paper 84.01, Milan.

Kopp, R., R. Morgenstern, W. Pizer and M. Toman. (1999), A Proposal for Credible Early Action in U.S. Climate Policy. Washington D.C.: RFF.

Krugman, O. (1991), Is Bilaterism Bad? In E. Helpman and A Razin (eds.), International Trade and Trade Policy. MIT Press: Cambridge.

Manne, A. and R. Richels (1999), The Kyoto Protocol: a cost-effective strategy for meeting environmental objectives? in J. Weyant, ed., The Cost of the Kyoto Protocol: A Multi-Model Evaluation, Special Issue of the Energy Journal.

Manne, A.S. and R.G. Richels (2001), US Rejection of the Kyoto Protocol: The Impact on Compliance Costs and CO2 Emissions. Working Paper 01-12, AEI-Brookings Joint Center for Regulatory Studies.

McKibbin, W.J. and P.J. Wilcoxen (1997),“A Better Way to Slow Global Climate Change, The Brookings Institution Policy Brief, July.

News.com.au, Aus, US launch climate plan, July 2 2002. Online at www.news.com.au

Nordhaus, W.D. and Z. Yang (1996), A regional dynamic generalequilibrium model of alternative climate-change strategies, American Economic Review, 4, 741-765.

Nordhaus, W.D. (2001), After Kyoto: Alternative Mechanisms to Control Global Warming, Presentation at the $20^{\text {th }}$ Anniversary Meeting of the International Energy Workshop, IIASA, Laxenburg, Austria.

OECD/IEA (2002), Beyond Kyoto: Energy Dynamics and Climate Stabilisation. Paris. 
Pizer, W. (1999), Choosing Price or Quantity Controls for Greenhouse Gases, Climate Issues Brief No. 17, Resources for the Future, Washington D.C.

Ray, D. and R. Vohra (1997), Equilibrium Binding Agreements, Journal of Economic Theory, 73, 30-78.

Ray, D. and R. Vohra (1999), A Theory of Endogenous Coalition Structures, Games and Economic Behavior, 26, 286-336.

Reinstein, R. A. (2004), A Possible Way Forward on Climate Change, mimeo, Reinstein \& Associates Inc.

Sampson, G. and S. Woolcock (2003), Regionalism, Multilateralism, and Economic Integration. The Recent Experience, Tokyo, the United Nations University Press.

Stewart, R and J. Wiener (2003), Reconstructing Climate Policy, American Enterprise Institute Press.

The Japan Times, China could help Japan by taking its money and cutting its Kyoto target, January $26^{\text {th }}, 2002$. Online at www.japantimes.com

The Washington Times, Overseas, U.S. firms warm up to Kyoto, January $24^{\text {th }}, 2002$. Online at www.japantimes.com

Tjornhom J. (2000), Dynamic Trade Bloc Formation: Building Blocs or Stumbling Blocs? University of Minnesota

Yi, S.-S. (1996a), Endogenous Formation of Customs Unions under Imperfect Competition: Open Regionalism is Good. Journal of International Economics, Vol. 41 (1996), 153-177.

Yi, S.-S. (1996b), Open Regionalism and World Welfare. Eastern Economic Journal, Vol. 22, No. 4, Fall 1996, 467-475.

Yi, S.-S. (1997), Stable Coalition Structures with Externalities, Games and Economic Behaviour, 20, 201-23.

Yi, S.-S. (1998), Free trade Areas and Welfare: An Equilibrium Analysis. Dartmouth College, Department of Economics.

Yi, S.-S. (2003), Endogenous Formation of Economic Coalitions: A Survey of the Partition Function Approach. In: C. Carraro (ed.), Endogenous Formation of Economic Coalitions, Edward Elgar, Cheltenham, UK, pp. 80-127.

Yi, S.-S. and H. Shin (1995), Endogenous Formation of Coalitions: Oligopoly, mimeo, Department of Economics, Dartmouth College. 